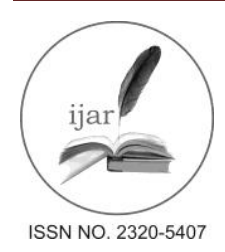

\author{
Journal homepage: http://www.journalijar.com

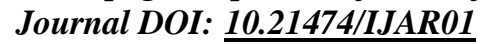

INTERNATIONAL JOURNAL

OF ADVANCED RESEARCH

RESEARCH ARTICLE

\title{
GC-MS ANALYSIS AND ANTIMICROBIAL ACTIVITY OF FIXED OIL FROM SUDANESE PEGANUM HARMALA L. (ZYGOPHYLLACEAE).
}

\author{
${ }^{*}$ Abdel Karim. M. ${ }^{1}$, Zohor, M. ${ }^{2}$ and Sufian,A. ${ }^{3}$ \\ 1. Sudan University of Science and Technology, Faculty of Science, Dept. of Chemistry. \\ 2. Institute of Industrial Consultancy and Research \\ 3. Taibah University,Faculty of Science, Dept. of Chemistry
}

\section{Manuscript Info}

Manuscript History:

Received: 12 April 2016

Final Accepted: 19 May 2016

Published Online: June 2016

Key words:

Peganum harmala, Fixed oil ,GC-

MS, Antimicrobial Activity.

*Corresponding Author

\begin{abstract}
This study was planned to identify and quantify the lipid composition of Sudanese Peganum harmala (L.) seeds and to evaluate the potential antimicrobial activity of the extracted fixed oil . GC- MS analysis of the fixed oil revealed the presence of : 9,12- octadecadienoic acid (49.76\%),9octadecenoic acid (19.30\%), hexadecanoic acid(10.86\%), , methyl stearate $(6.37 \%)$ beside other minor constituents. In cup plate agar diffusion assay, the oil was screened for antimicrobial activity against six standard human pathogens and promising results were obtained.
\end{abstract}

Abdel Karim. M. Copy Right, IJAR, 2016. All rights reserved.

\section{Introduction:-}

Peganum harmala L. (Zygophyllaceae) is native to eastern Mediterranean region. Due to resemblance to plants of the rue family, It is also known as Wild Rue or Syrian Rue(Mikaili ,2012). Peganum harmala is a perennial plant which can grow to about $0.8 \mathrm{~m}$ tall, but normally it is about $0.3 \mathrm{~m}$ tall. It blossoms between June and August in the northern hemisphere. The roots of the plant can reach a depth of up to $6.1 \mathrm{~m}$, if the soil is very dry. The flowers are white and are about $2.5-3.8 \mathrm{~cm}$ in diameter. The round seed capsules measure about $1-1.5 \mathrm{~cm}$ in diameter(Frison $e t$. al.,2008; El Gendy et.al.,2009; Wanntorp et.al.,2012; Sheahan et.al.,2000).

Peganum harmala is used traditionally in the treatment of a wide array of human disorders. $\beta$-Carboline alkaloids were identified in different parts(seeds,roots,barks) of Peganum harmala. Various pharmacological surveys demonstrated that harmala alkaloids namely; harmaline, harmine, harmalol and harmol are biologically active compounds.

The plant is employed in ethno-medicine to treat hypertension and cardiac disease(Tahraoui et.al.,2007; Fortunato et.al.,2009). Extracts of seeds exert vasorelaxant effects(Hamsa and Kuttan,2010) and alkaloids of Peganum harmala were shown to have anti-platelet aggregation effects(Saeed et.al.,1993).Furthermore,these alkaloids were shown to be psychoactive in mammalian body(Airaksinen and Kari , 1981).Various studies demonstrated a wide range of effects produced by Peganum harmala extracts on the central nervous system including ; analgesic(Airaksinen and Kari , 1981; Monsef and Ghobadi ,2004),hallucination, excitation (Nasehi et.al.,2010) and antidepressant(Fortunato et.al. ,2009; Farzin et.al.,2006) effects.Harmal alkaloids were shown to be involved in pathogensis of Parkinson`s disease(Splettstoesser et.al.,2005; Storch et.al.,2004).

Various studies indicated antiparasidal (Storch et.al.,2008; Akhtar et.al., 2000), antifungal (Akhtar ,2010;Saadabi,2006), anti-bacterial (Akhtar,2010; Prashanth and John,1999) and insecticidal (Rharrabe et.al., 2007; Jbilou et.al.,2008) effects for Harmal alkaloids. 
Significant in vitro and in vivo antileishmanial activity was exhibited by Peganum harmala seeds extract(RahimiMoghaddam et.al.,2011). Also it was reported that methanolic extracts of Peganum harmala reduced the number of living pups and produced a dose- dependent decrease in litter size of model animals(Shapira et.al.,1989). Frequent abortion is observed in animals that digest this plant in dry seasons(Mahmoudian et.al.,2002).

Recently there has been renewed interest in the use of medicinal plants by local communities to treat a broad spectrum of human disorders. In parallel there has been an increased scientific interest in the bioconstituents(steroids,alkaloids,flavonoids....etc) of these plants. A knowledge of bio-active components would evidently site a rationale for traditional uses of medicinal plants and enrich the global database of phytochemicals. The constituents and the antimicrobial potential of Peganum harmala oil were addressed by many authors. However, such constituents are influenced to some extent by geographical distribution. To the best of our knowledge there are no reports addressing the constituents and antimicrobial potency of the Sudanese material of Peganum harmala fixed oil. So we planned this study to evaluate the antimicrobial activity of fixed oil from Peganum harmala native to Sudan and to probe the constituents present in this oil.

\section{Materials and Methods:-}

\section{Plant material:-}

Seeds of Peganum harmala were collected from a forest reserve at "Hawata" - eastern Sudan.The plant was identified by direct comparison with reference herbarium sample.

\section{Instruments:-}

A Shimadzo GC-MS-QP2010 Ultra instrument with a RTX-5MS column (30m,length ; 0.25mm diameter ; $0.25 \mu \mathrm{m}$, thickness)was used.

\section{Test organisms:-}

Peganum harmala oil was screened for antibacterial and antifungal activities using the standard microorganisms shown in Table(1).

Table 1: Test organisms.

\begin{tabular}{|c|c|c|}
\hline $\begin{array}{c}\text { Ser. } \\
\text { No }\end{array}$ & Micro-organism & Type \\
\hline 1 & Bacillus subtilis & G+ve \\
\hline 2 & Staphylococcus aureus & G+ve \\
\hline 3 & Pseudomonas aeroginosa & G-ve \\
\hline 4 & Escherichia coli & G-ve \\
\hline 5 & Aspergillus niger & fungi \\
\hline 6 & Candida albicans & fungi \\
\hline
\end{tabular}

\section{Methods:-}

Extraction of oil from Peganum harmala seeds:-

Powdered shade-dried seeds of Peganum harmala (300g) were exhaustively extracted with $\mathrm{n}$-hexane (soxhlet).The solvent was removed under reduced pressure and the oil was kept in the fridge at $4^{\circ} \mathrm{C}$ for further manipulation.

\section{Esterification of oil:-}

A Methanolic solution of sodium hydroxide was prepared by dissolving (2g) of sodium hydroxide in 100ml methanol.A stock solution of methanolic sulphuric acid was prepared by mixing ( $1 \mathrm{ml}$ )of concentrated sulphuric acid with $(99 \mathrm{ml})$ methanol.

The oil $(2 \mathrm{ml})$ was placed in a test tube and $7 \mathrm{ml}$ of alcoholic sodium hydroxide were added followed by $7 \mathrm{ml}$ of alcoholic sulphuric acid. The tube was stoppered and shaked vigorously for five minutes and then left overnight.(2ml) of supersaturated sodium chloride were added, then $(2 \mathrm{ml})$ of normal hexane were added and the tube was vigorously shaked for five minutes .The hexane layer was then separated. $(5 \mu \mathrm{l})$ of the hexane extract were mixed with $(5 \mathrm{ml})$ diethyl ether. The solution was filtered and the filtrate $(1 \mu \mathrm{l})$ was injected in the GC-MS vial. 


\section{GC-MS analysis:-}

Peganum harmala fixed oil was analyzed by gas chromatography - mass spectrometry. A Shimadzo GC-MSQP2010 Ultra instrument with a RTX-5MS column (30m,length ; $0.25 \mathrm{~mm}$ diameter ; $0.25 \mu \mathrm{m}$, thickness)was used. Helium (purity; $99.99 \%$ ) was used as carrier gas. Oven temperature program is given in Table 2 and other chromatographic conditions are depicted in Table 3 .

Table 2:- Oven temperature program.

\begin{tabular}{|c|c|c|}
\hline Rate & Temperature $\left({ }^{\circ} \mathrm{C}\right)$ & Hold Time $\left(\right.$ min. $\left.^{-1}\right)$ \\
\hline- & 150.0 & 1.00 \\
4.00 & 300.0 & 0.00 \\
\hline
\end{tabular}

Table 3:- Chromatographic conditions.

\begin{tabular}{|ll|}
\hline Column oven temperature & $150.0^{\circ} \mathrm{C}$ \\
Injection temperature & $300.0^{\circ} \mathrm{C}$ \\
Injection mode & Split \\
Flow control mode & Linear velocity \\
Pressure & $139.3 \mathrm{KPa}$ \\
Total flow & $50.0 \mathrm{ml} / \mathrm{min}$ \\
Column flow & $1.54 \mathrm{ml} / \mathrm{sec}$. \\
Linear velocity & $47.2 \mathrm{~cm} / \mathrm{sec}$. \\
Purge flow & $3.0 \mathrm{ml} / \mathrm{min}$. \\
Spilt ratio & -1.0 \\
\hline
\end{tabular}

\section{Antimicrobial assay:- \\ Preparation of bacterial suspensions:-}

One $\mathrm{ml}$ aliquots of 24 hours broth culture of the test organisms were aseptically distributed onto nutrient agar slopes and incubated at $37^{\circ} \mathrm{C}$ for 24 hours.

The bacterial growth was harvested and washed off with sterile normal saline, and finally suspended in $100 \mathrm{ml}$ of normal saline to produce a suspension containing about $10^{8}-10^{9}$ colony forming units per ml. The suspension was stored in the refrigerator at $4^{\circ} \mathrm{C}$ until used. The average number of viable organism per $\mathrm{ml}$ of the stock suspension was determined by means of the surface viable counting technique.

Serial dilutions of the stock suspension were made in sterile normal saline in tubes and one drop volumes (0.02 ml) of the appropriate dilutions were transferred by adjustable volume micropipette onto the surface of dry nutrient agar plates. The plates were allowed to stand for two hours at room temperature for the drop to dry, and then incubated at $37^{\circ} \mathrm{C}$ for 24 hours.

\section{Preparation of fungal suspensions:-}

Fungal cultures were maintained on dextrose agar incubated at $25^{\circ} \mathrm{C}$ for four days. The fungal growth was harvested and washed with sterile normal saline, and the suspension was stored in the refrigerator until used.

\section{Testing for antibacterial activity:-}

The cup-plate agar diffusion method was adopted, with some minor modifications, to assess the antibacterial activity. (2ml) of the standardized bacterial stock suspension were mixed with $200 \mathrm{ml}$ of sterile molten nutrient agar which was maintained at $45^{\circ} \mathrm{C}$ in a water bath. $(20 \mathrm{ml})$ Aliquots of the incubated nutrient agar were distributed into sterile Petri dishes. The agar was left to settle and in each of these plates which were divided into two halves, two cups in each half (10 $\mathrm{mm}$ in diameter) were cut using sterile cork borer (No 4), each one of the halves was designed for one of the test solutions. Separate Petri dishes were designed for standard antibacterial chemotherapeutics (ampicillin and gentamycin).

The agar discs were removed, alternate cups were filled with $0.1 \mathrm{ml}$ samples of each test solution using adjustable volume microtiter pipette and allowed to diffuse at room temperature for two hours. The plates were then incubated in the upright position at $37^{\circ} \mathrm{C}$ for 24 hours. 
The above procedure was repeated for different concentrations of the test solutions and the standard chemotherapeutics. After incubation, the diameters of the resultant growth inhibition zones were measured in triplicates and averaged.

\section{Results and Discussion:-}

\section{GC-MS analysis of Peganum harmala fixed oil:-}

GC-MS analysis of Peganum harmala oil was conducted and the identification of the constituents was initially accomplished by comparison with the MS library (NIST) and further confirmed by interpreting the observed fragmentation pattern .Comparison of the mass spectra with the database on MS library revealed about $90-95 \%$ match.

\section{Constituents of oil:-}

The GC-MS spectrum of the studied oil revealed the presence of 43 components(Table 4).The typical total ion chromatograms(TIC) is depicted in Fig.1.

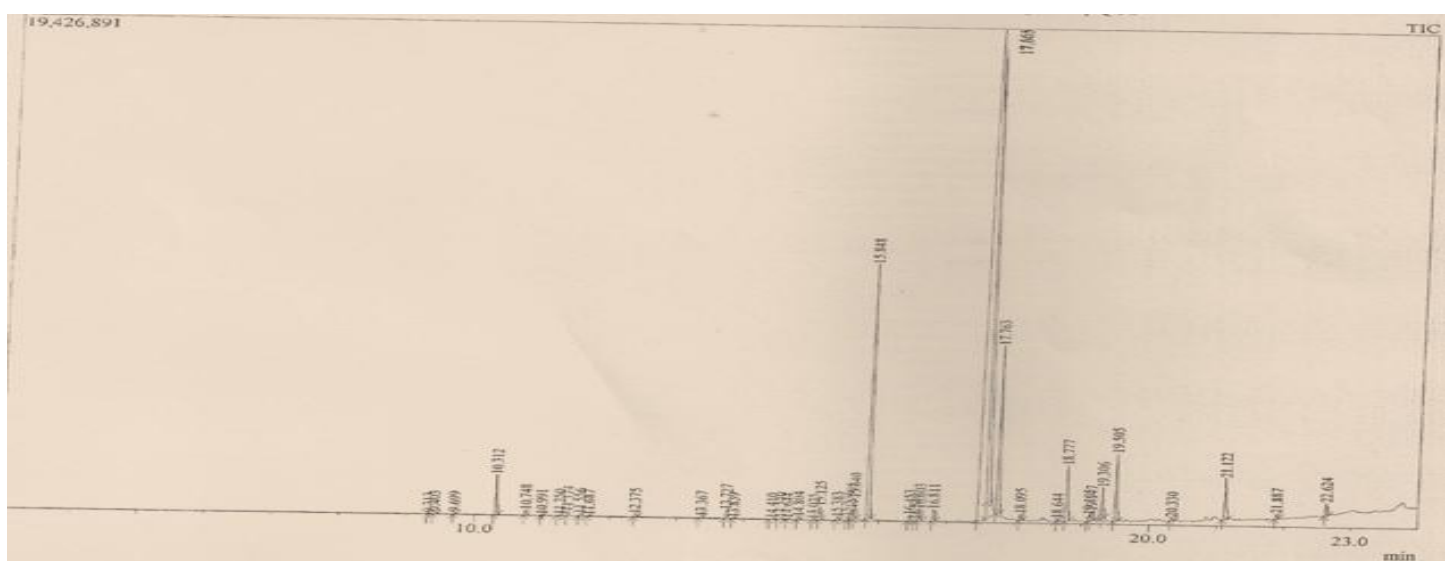

Fig. 1:- Cromatograms of Peganum harmala oil. 
Table 4:- Constituents of Peganum harmala oil.

\begin{tabular}{|c|c|c|c|c|}
\hline \multicolumn{5}{|c|}{ Peak Report TIC } \\
\hline Peak\# & R.Time & Area & Area $\%$ & Name \\
\hline 1 & 9.313 & 38106 & 0.02 & .alpha.-Cubebene \\
\hline 2 & 9.403 & 161408 & 0.08 & Eugenol \\
\hline 3 & 9.699 & 117267 & 0.06 & -alfa,-Copaene \\
\hline 4 & 10.312 & 2534770 & 1.28 & Caryophyllene \\
\hline 5 & 10.748 & 307066 & 0.16 & 1,4,7,-Cycloundecatriene, 1,5,9,9-tetramet \\
\hline 6 & 10.991 & 33949 & 0.02 & gamma,-Muurolene \\
\hline 7 & 11.250 & 58704 & 0.03 & .alpha.-Farnesene \\
\hline 8 & 11.374 & 237716 & 0.12 & Butylated Hydroxytoluene \\
\hline 9 & 11.556 & 126716 & 0.06 & Naphthalene, $1,2,3,5,6,8$ a-hexahydro-4,7-d \\
\hline 10 & 11.687 & 37042 & 0.02 & Naphthalene, $1,2,3,4,4 a, 7$-hexahydro-1,6-d \\
\hline 11 & 12.375 & 172655 & 0.09 & 1H-Cycloprop[e]azulen-4-ol, decahydro-1, \\
\hline 12 & 13.367 & 98368 & 0.05 & Santalol, cis, ,alpha.- \\
\hline 13 & 13.727 & 493507 & 0.25 & Methyl tetradecanoate \\
\hline 14 & 13.839 & 35339 & 0.02 & .beta.-Santalol \\
\hline 15 & 14.410 & 47077 & 0.02 & Methyl 13-methyltetradecanoate \\
\hline 16 & 14.540 & 93168 & 0.05 & 5-Octadecenoic acid, methyl ester \\
\hline 17 & 14.644 & 57896 & 0.03 & 6-Octadecenoic acid, methyl ester \\
\hline 18 & 14.804 & 163133 & 0.08 & Pentadecanoic acid, methyl ester \\
\hline 19 & 15.025 & 18141 & 0.01 & 2-Pentadecanone, 6,10,14-trimethyl- \\
\hline 20 & 15.125 & 769918 & 0.39 & Musk ambrette (artificial) \\
\hline 21 & 15.383 & 228703 & 0.12 & n-Nonadecanol-1 \\
\hline 22 & 15.536 & 197684 & 0.10 & 7,10-Hexadecadienoic acid, methyl ester \\
\hline 23 & 15.595 & 777759 & 0.39 & Methyl hexadec-9-enoate \\
\hline 24 & 15.640 & 1221537 & 0.62 & 9-Hexadecenoic acid, methyl ester, (Z)- \\
\hline 25 & 15.848 & 21455053 & 10.86 & Hexadecanoic acid, methyl ester \\
\hline 26 & 16.453 & 337846 & 0.17 & Hexadeeanoic acid, 15-methyl-, methyl est \\
\hline 27 & 16.540 & 91310 & 0.05 & Hexadecanoic acid, 14-methyl-, methyl est \\
\hline 28 & 16.603 & 768084 & 0.39 & cis-10-Heptadecenoic acid, methyl ester \\
\hline 29 & 16.811 & 743750 & 0.38 & Heptadecanoic acid, methyl ester \\
\hline 30 & 17.565 & 98353486 & 49.76 & 9,12-Octadecadienoic acid $(\mathrm{Z}, \mathrm{Z})$-, methyl \\
\hline 31 & 17.605 & 38154905 & 19.30 & 9-Octadecenoic acid (Z)-, methyl ester \\
\hline 32 & 17.763 & 12582612 & 6.37 & Methyl stearate \\
\hline 33 & 18.095 & 391479 & 0.20 & Cyclopropaneoctanoic acid, 2-octyl-, meth \\
\hline 34 & 18.644 & 144498 & 0.07 & Nonadecanoic acid, methyl ester \\
\hline 35 & 18.777 & 3907267 & 1.98 & Methyl 9.cis.,11.trans.t,13.trans.-octadecat \\
\hline 36 & 19.105 & 437657 & 0.22 & Methyl 5,13-docosadienoate \\
\hline 37 & 19.147 & 605638 & 0.31 & gamma,-Linolenic acid, methyl ester \\
\hline 38 & 19.306 & 2002847 & 1.01 & 11-Eicosenoic acid, methyl ester \\
\hline 39 & 19.505 & 4871911 & 2.46 & Methyl 18-methylnonadecanoate \\
\hline 40 & 20.330 & 219451 & 0.11 & Heneicosanoic acid, methyl ester \\
\hline 41 & 21.122 & 3239274 & 1.64 & Methyl 20-methyl-heneicosanoate \\
\hline 42 & 21.887 & 351954 & 0.18 & Tricosanoic acid, methyl ester \\
\hline 43 & 22.624 & 964636 & 0.49 & Tetracosanoic acid, methyl ester \\
\hline & & 197651287 & 100.00 & \\
\hline
\end{tabular}


The following important constituents were detected:

\section{9-Octadecenoic acid methyl ester(19.30\%):-}

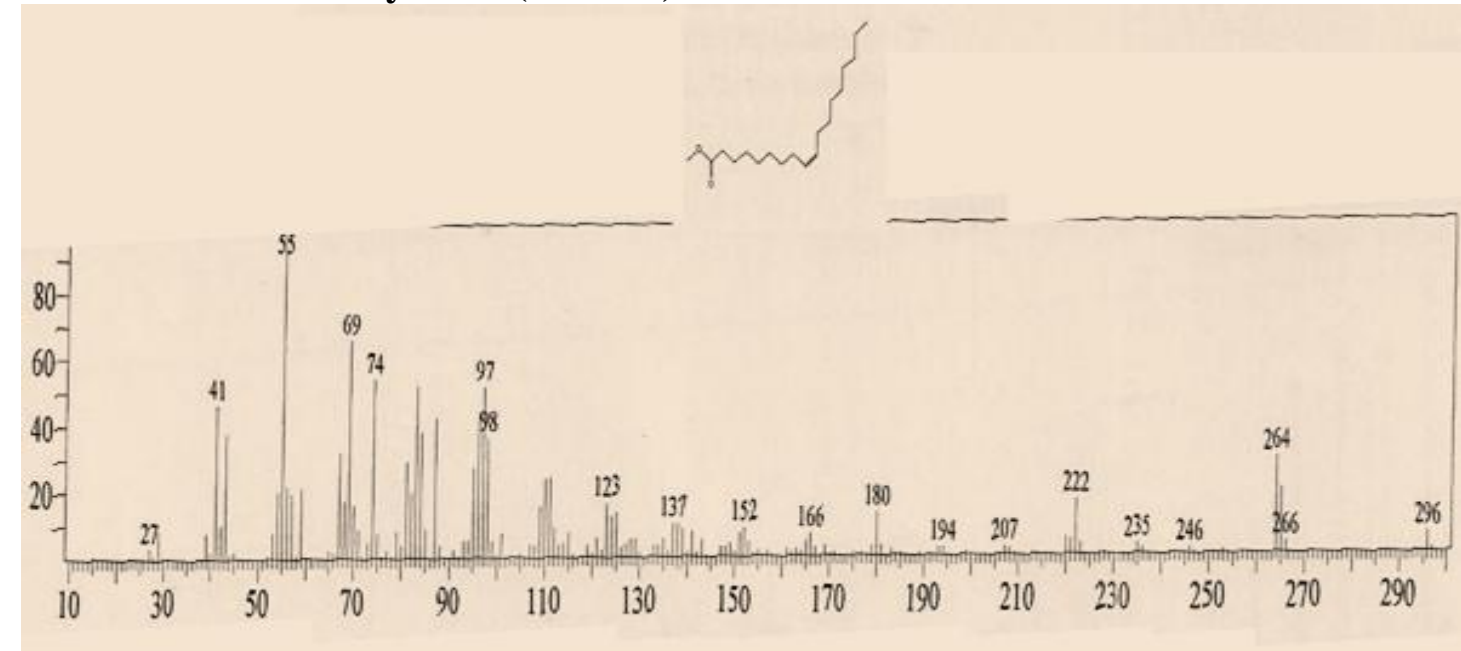

Fig. 2:- Mass spectrum of 9-octadecenoic acid methyl ester.

The EI mass spectrum of 9-octadecenoic acid methyl ester is shown in Fig. 2.The peak at $\mathrm{m} / \mathrm{z} 296$, which appeared at R.T. 17.605 in total ion chromatogram, corresponds to $\mathrm{M}^{+}\left[\mathrm{C}_{19} \mathrm{H}_{36} \mathrm{O}_{2}\right]^{+}$. The peak at $\mathrm{m} / \mathrm{z} 266$ is due to loss of a methoxyl function.

As part of animal fats and vegatables, 9-octadecenoic acid(oleic acid) is included in the normal human diet.It is used as emollient(Currasco,2002). It is also a major component of soap. The acid is used in small amounts as excipient in pharmaceutical industries and as soldening flux in stained glass work .Oleic acid is a common monounsaturated fat in human diet. This acid may be responsible for the hypotensive potential of olive oil(Terese et.al.,2008).The consumption of oleate in olive oil has been associated with decreased risk of breast cancer(MartinMoreno et.al.,1994)

\section{9,12-Octadecadienoic acid methyl ester $(49.76 \%)$ :-}

The EI mass spectrum of 9,12-octadecadienoic acid methyl ester is shown in Fig.3 .The peak at $\mathrm{m} / \mathrm{z} 294$, which appeared at R.T. 17.565 in total ion chromatogram, corresponds to $\mathrm{M}^{+}\left[\mathrm{C}_{19} \mathrm{H}_{34} \mathrm{O}_{2}\right]^{+}$. The peak at $\mathrm{m} / \mathrm{z} 263$ corresponds to loss of a methoxyl function.

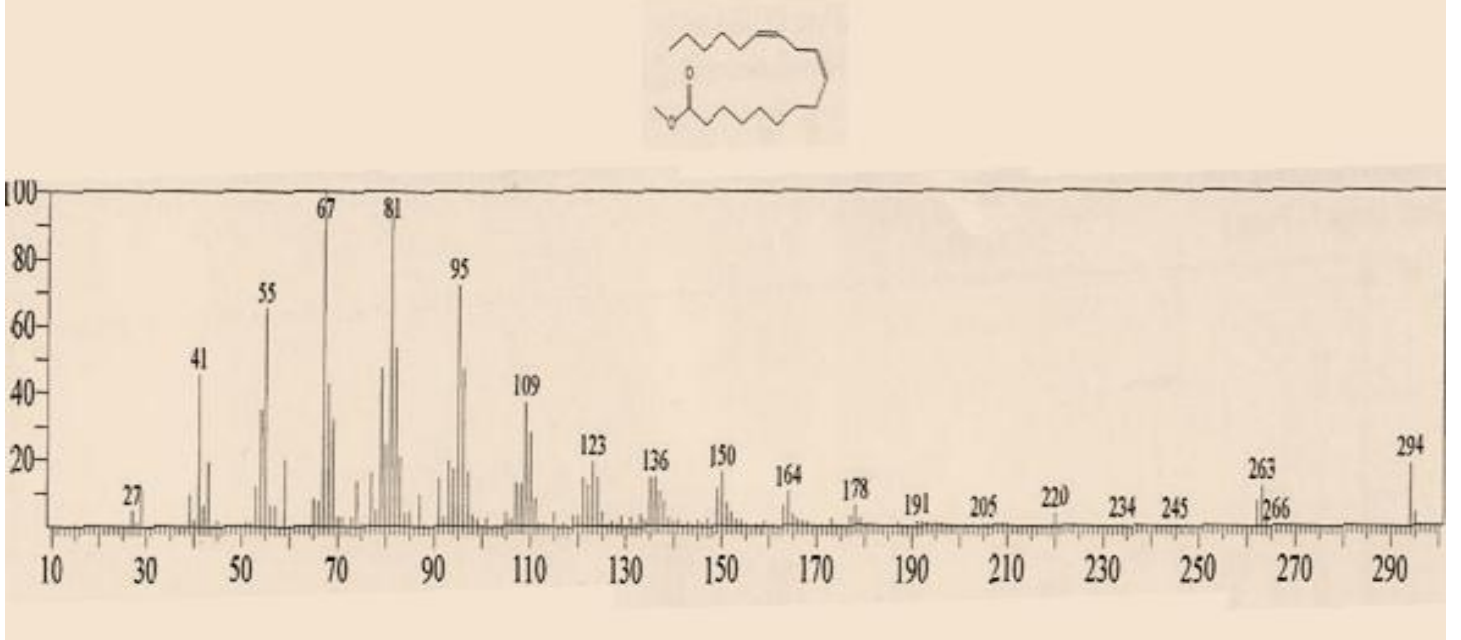

Fig. 3:- Mass spectrum of 9,12-octadecadienoic acid methyl ester 
9,12-Octadecadienoic(linoleic acid) belongs to one of the two families of essential fatty acids. Such acids can not be synthesized by human bodies and are available through diet(Burr et.al.,1930).Linoleic acid is used in the biosynthesis of arachidonic acid .It exists in lipids of cell membrane. Rich sources are: nuts and fatty seeds. 9,12Octadecadienoic is converted by some enzymes like lipoxygenases into mono-hydroxy products which are enzymatically oxidized to keto metabolites.Such metabolites are implicated in human physiology and pathology.Linoleate deficiency caused mild skin scaling,hair loss and poor wound healing in model animals(Cunnane and Anderson,1997; Ruthig and Mecklung-Gill,1999).

\section{Hexadecanoic acid methyl ester(10.86\%):-}

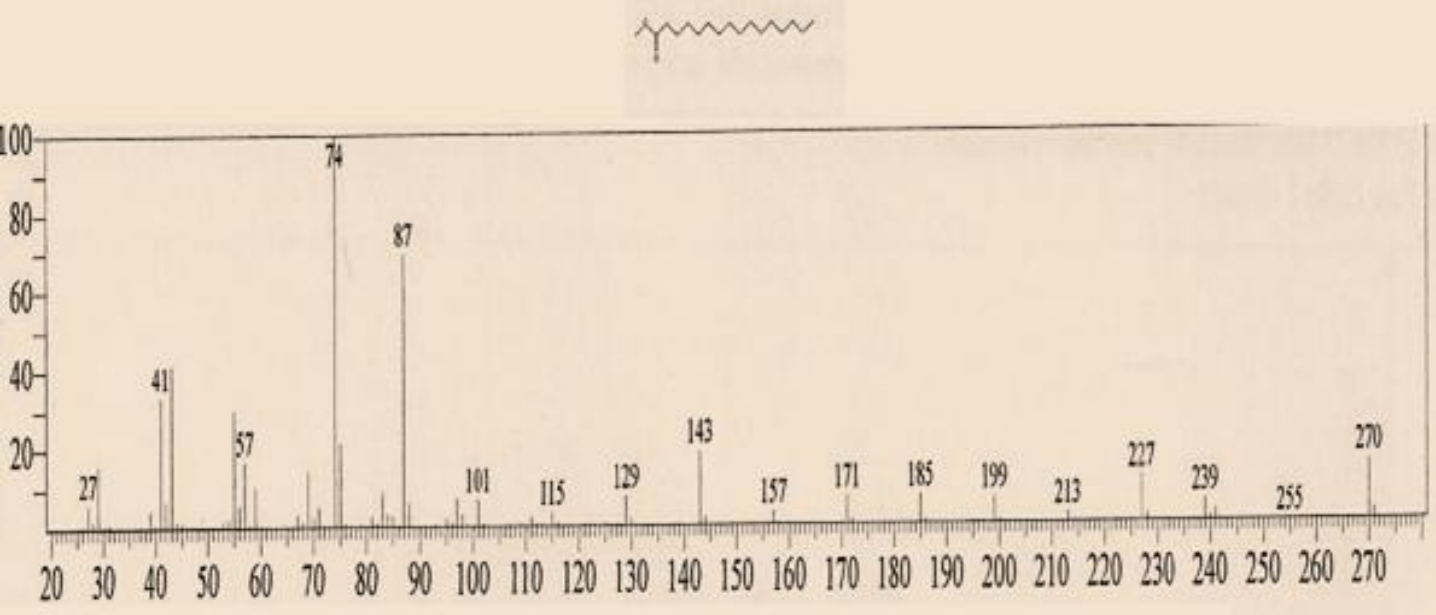

Fig. 4:- Mass spectrum of hexadecanoic acid methyl ester.

The EI mass spectrum of hexadecanoic acid methyl ester is shown in Fig. 4. The peak at $\mathrm{m} / \mathrm{z} 270$, which appeared at R.T. 15.848 in total ion chromatogram, corresponds to $\mathrm{M}^{+}\left[\mathrm{C}_{17} \mathrm{H}_{34} \mathrm{O}_{2}\right]^{+}$. The peak at $\mathrm{m} / \mathrm{z} 239$ is due to loss of a methoxyl function.

hexadecanoic acid(palmitic acid) is a saturated fatty acid . In plants and humans, it is the most common fatty acid.During the synthesis of fatty acids , palmitic acid is produced first(Gunstone et.al.,2007). It is the precursor of long-chain fatty acids .This acid is a major lipid component of human breast milk(Kingsbury et.al.,1961; Jensen et.al.,1978).Palmitic acid is used in production of soaps and cosmetics, it is also widely used in food industry .

\section{Methyl stearate(6.37\%):-}

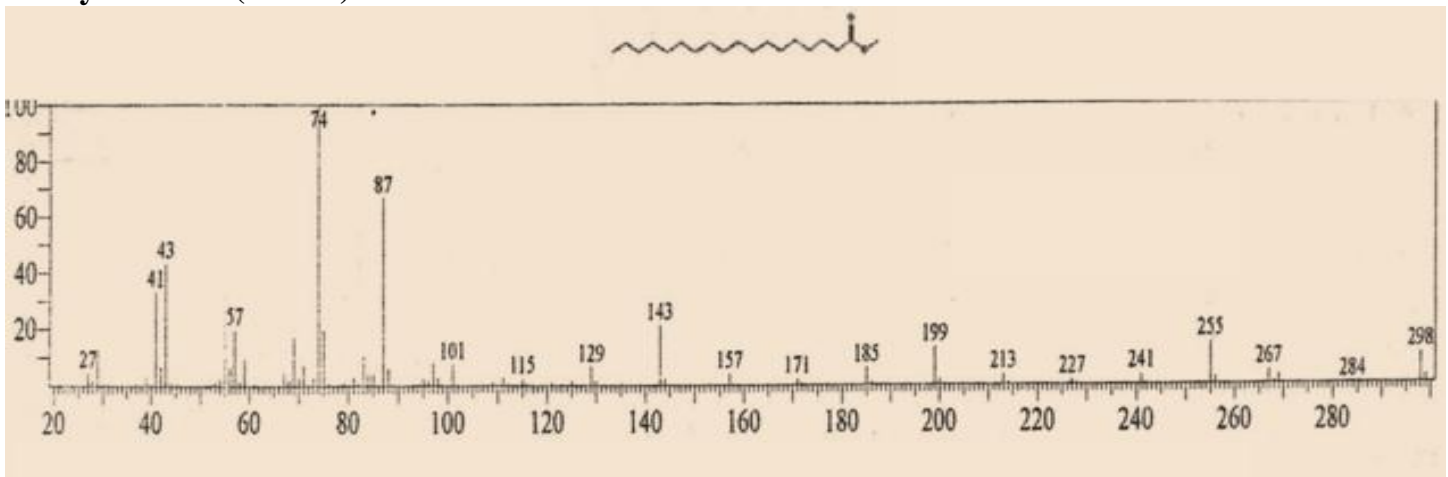

Fig. 5:- Mass spectrum of methyl stearate.

The EI mass spectrum of methyl stearate is shown in Fig. 5.The peak at $\mathrm{m} / \mathrm{z} 298$, which appeared at R.T. 17.763 in total ion chromatogram, corresponds to $\mathrm{M}^{+}\left[\mathrm{C}_{19} \mathrm{H}_{38} \mathrm{O}_{2}\right]^{+}$. The peak at $\mathrm{m} / \mathrm{z} 267$ corresponds to loss of a methoxyl function. 


\section{Antibacterial activity:-}

In cup plate agar diffusion assay, the oil was evaluated for antimicrobial activity. The averages of the diameters of the growth inhibition zones are shown in Table (5).The results were interpreted in terms of the commonly used terms ; <9mm: inative;9-12 mm:partially active;13-18mm: active; $>18 \mathrm{~mm}$ :very active) .Tables (6) and (7) represent the antimicrobial activity of standard antibacterial and antifungal chemotherapeutic agents again st standard bacteria and fungi respectively.

Table 5:- Antibacterial activity of Peganum harmala oil : M.D.I.Z(,mm)

\begin{tabular}{|c|c|c|c|c|c|c|c|}
\hline Drug & Conc. $(\mathrm{mg} / \mathrm{ml})$ & Ec & Ps & Sa & Bs & Ca & An \\
\hline oil & 100 & 15 & 9 & 17 & 17 & 16 & 18 \\
\hline
\end{tabular}

Table 6:- Antibacterial activity of standard chemotherapeutic agents :M.D.I.Z (mm)

\begin{tabular}{|c|c|c|c|c|c|}
\hline Drug & $\begin{array}{c}\text { Conc. } \\
\mathrm{mg} / \mathrm{ml}\end{array}$ & Bs. & Sa. & Ec. & Ps. \\
\hline Ampicillin & 40 & 15 & 30 & - & - \\
& 20 & 14 & 25 & - & - \\
& 10 & 11 & 15 & - & - \\
\hline Gentamycin & 40 & 25 & 19 & 22 & 12 \\
& 20 & 22 & 18 & 15 & 12 \\
\hline
\end{tabular}

Table 7:- Antifungal activity of standard chemotherapeutic agent against standard fungi.

\begin{tabular}{|c|c|c|c|}
\hline Drug & Conc. & An. & Ca. \\
\hline Clotrimazole & $\mathrm{mg} / \mathrm{ml}$ & 22 & 38 \\
& 10 & 17 & 31 \\
& 7.5 & 16 & 29 \\
\hline
\end{tabular}

* Sa.: Staphylococcus aureus

* Ec.: Escherichia coli

* Pa.: Pseudomonas aeruginosa

* An.: Aspergillus niger

* Ca.: Candida albicans

* Bs.: Bacillus subtilis

The oil showed activity against all test organisms,but it was partially active against Pseudomonas aeruginosa. Significant activity was observed against the Gram positive bacteria: Staphylococcus aureus, Bacillus subtilis and and the fungus Aspergillus niger .Thus the oil is a plausible candidate for further optimization.

\section{References:-}

1. Astulla, A, Zaima, K., Matsuno, Y., Hirasawa, Y., Ekasari, W., Widyawaruyanti, A.(2008) ,J Nat Med , $62,470$.

2. Airaksinen, M.M., Kari, I. , Med. Bio.,59,190.

3. Akhtar, M.S., Iqbal,. Z, Khan, M..N, Lateef, M.(1981), Small Rumin Res ,38,99.

4. Burr,G.O.,Burr,M.,Miller,E.(1930),J.Biol.Chem.,86,587.

5. Cunnane,S.,Anderson,M.(1997), J.Lipid Res.,38(4),805.

6. Carresco.F.(2002), "Ingradients de Cosmeticos" ,Dictionario De Ingredientes, $4^{\text {th }}$ ed.,P428 : ISBN 978-84-6134979-1.

7. Collins, M..A, (2003). J Neurochem,89,685.

8. Duncom,A.(2000), " The Technique of Leaded Glass",P.77 : ISBN 0-486-42607-6.

9. El Gendy, M.A., El-Kadi, A.O. (2009), Drug Metab Lett,3,212.

10. Frison, G., Favretto, D., Zancanaro, F., Fazzin, G., Ferrara, S.D. (2008),, Forensic Sci Int. ,179 ,37.

11. Fortunato ,J.J., Réus, G.Z., Kirsch, T.R., Stringari ,R.B., Stertz, L., Farzin, D., Mansouri, N. (2006), Eur Neuropsychopharmacol, 16,324.

12. Gunstone,F.D.,John,L.,Albert,J.(2007) "The Lipid Handbook", $3^{\text {rd }}$ ed., Boca Raton, CRC Press.

13. Hamsa, T.P., Kuttan, G. (2010),, Eur J Pharmacol.,649,64.

14. Jbilou, R., Amri, H., Bouayad ,N., Ghailani, N., Ennabili, A., Sayah, F. (2008), Bioresour Technol, 99 ,959. 
15. Jensen,R.G.,Hagerty,M.M. and Mc-Mahon ,K.E.(1978), Am.J.Clin.Nut.,31(6),990.

16. Kapczinski F., (2009), Neuropsychopharmacol. Biol. Psychiatry, 33,1425.

17. Kingsbury,K.J.,Paul,S.,Crossley,A.,Morgan,D.(1961) ,Biochemical Journal,78,541.

18. Mikaili ,P., Sharifi, M., SHayegh, J.,Sarahroodi, S.H.(2012), , Int J Anim Vet Adv , 4,40.

19. Monsef, H.R., Ghobadi, A., Iranshahi, M.,, Abdollahi M. (2004), J Pharm Pharm Sci ,7, 65.

20. Mahmoudian, M., Jalilpour, H., Salehian, P. (2002), Iran. J. Pharmacol. Therapeut.,1, 11.

21. Nasehi, M., Piri, M., Nouri, M., Farzin, D., Nayer-Nouri, T., Zarrindast, M.R. (2010), Eur. J. Pharmacol., 634,77.

22. Martin,M.,Jose,M.,Lydia,B.,Jose,R.,Rodinguez,A.,F.,Fermandez,R.,Juan,C.,Maisonneuve,P.(1994),Intenationa l Journal of Cancer,58(6),774.

23. Nenaah, G. (2004),Fitoterapia,81,779.

24. Prashanth, D., John, S. (2010), Fitoterapia ,70,438.

25. Rharrabe, K., Bakrim, A., Ghailani, N., Sayah, F.(2007), Pestic Biochem Physiol,89,137.

26. Rahimi-Moghaddam, P., Ebrahimi, S.A., Ourmazdi, H., Selseleh, M., Karjalian, M., Haj-Hassani, G. (2011) , J. Res. Med. Sci.,161032.

27. Ruthig,D.J., Meckling-Gill,K.A. (1999), Journal of Nutrition,129(10), 179.

28. Shapira, Z., Terkel. J., Egozi, Y., Nyska, A., Fiedman, J. J. Ethnopharmacol. 27 (1989) 319.

29. Sheahan, C.M, Chase, W.M. (2000), Syst Bot.,25,371.

30. Saeed, S.A., Farnaz, S., Simjee, R.U., Malik, A. (1993), Biochem SocTrans.,21,462

31. Saadabi, A.M.( 2005), Asian J. Plant Sci. ,5,907.

32. Splettstoesser, F., Bonnet, U., Wiemann, M., Bingmann, D., Büsselberg, D. (2005), Br J Pharmacol,144,52-8.

33. Tahraoui, A., El-Hilaly, J,Israili,Z.H.,Lyoussi, B. (2004), J Ethnopharmacol ,110,105.

34. Terese,S.,BarceloCoblinG.,Benet,M.,Alvarez,R.,Bressani,R.,Halver,J.E.,Escriba,P.V .(2008),Proceedings of the Natural Academy of Science,105(37),13811.

35. Wanntorp, L., Louis, P.( 2011) ,Swedish Museum of Natural History, In: Wanntorp L, editor." Flowers on the Tree of Life", Special Volume Series. Cambridge University Press, p. 326. 